\title{
A Proposal of a Life-Cycle for the Development of Sounding Rockets Missions
}

\author{
Felipe da Motta Silva ${ }^{1, \star}$ (D), Leonel Fernando Perondi ${ }^{2}$ (D)
}

1.Departamento de Ciência e Tecnologia Aeroespacial - Instituto de Aeronáutica e Espaço - Divisão de Eletrônica - São José dos Campos (SP), Brazil. 2.Instituto Nacional de Pesquisas Espaciais - Engenharia e Tecnologia Espaciais - São José dos Campos/SP - Brazil.

*Corresponding author: felipedamotta@gmail.com

\begin{abstract}
Suborbital flight experiments, carried out through sounding rockets, have been employed for scientific and technological research since the beginning of the space age, in the late 1950s. In Brazil, sounding rocket campaigns have been carried out since 1965, when the Centro de Lançamento Barreira do Inferno (CLBI) began its operation, having the Instituto de Aeronáutica e Espaço (IAE) as the primary provider of vehicles. IAE has also provided vehicles for international programs, such as the TEXUS and MASER microgravity programs, implemented by the European Space Agency (ESA), with launching campaigns based in the European territory. To implement each Brazilian mission that uses IAE's sounding rockets, a set of activities focused on mission objectives is planned and implemented. Although structured and executed quite similarly to a project, such sounding rocket campaigns do not have their complete life-cycle studied and formally described in phases, review meetings, management processes and verification and validation philosophy. In the present work, the attempt has been to characterize a sounding rocket mission as a project and then, based on European Cooperation for Space Standardization (ECSS) standards, propose a reduced life-cycle to develop such projects, tailored to meet Brazilian sounding rocket missions. The proposed life-cycle, adapted to Brazilian sounding rocket missions, is then compared with two other sounding rocket campaigns life-cycles: one from the European Programme for Life and Physical Sciences in Space and the other from the National Aeronautics and Space Administration (NASA) sounding rocket program. The study and availability of a framework for implementing and managing sounding rocket missions will improve the reliability of such endeavors and speed up their organization.
\end{abstract}

Keywords: Project life-cycle; Project management; Rocket mission.

\section{INTRODUCTION}

There has been a long-standing effort by the Brazilian government to develop space vehicles, mainly sounding rockets, aiming to provide access to outer space for scientific and technological experiments.

The development of space vehicles in Brazil has been carried out by the Instituto de Aeronáutica e Espaço (IAE). The IAE has developed a successful series of sounding rocket vehicles (Garcia et al. 2011), which have been extensively used by both Brazilian and international scientific programs, having the Instituto Nacional de Pesquisas Espaciais (INPE), the European Space Agency (ESA) and, lately, Brazilian universities as primary customers.

Received: Mar. 192020 | Accepted: Oct.13 2020

Peer Review History: Double Blind Peer Review.

Section Editor: Joana Ribeiro

This is an open access article distributed under the terms of the Creative Commons license. 
Besides the development of vehicles, the sounding rockets program of IAE supports customers in the development of missions in such disciplines as mission management, payload design, test and evaluation, customization of launch vehicles, recovery systems, launch range operations, tracking, data acquisition and processing, among others.

Examples of Brazilian supported missions include those from INPE, belonging to the program entitled Studies of the Ionosphere and Upper Atmosphere with experiments on board of sounding rockets and satellites, in which IAE provides sounding rocket vehicles and payload development support (Muralikrishna 2008). A second example is provided by a partnership program with Universidade Federal do Rio Grande do Norte, in which IAE provides support for payload development aimed at GPS equipment testing (Albuquerque 2009). A third example is given by a program carried out by IAE alone, which aims to develop technological payloads directed at improving the safety of future flights.

The IAE also provides vehicles for international programs, such as the TEXUS and MASER microgravity programs, implemented by the ESA, with launching campaigns based in the European territory.

As a final example, the Brazilian Microgravity Program (BMP), sponsored by the Agência Espacial Brasileira (AEB), is mentioned, which provides a microgravity environment for scientific and technological experiments. Flights on Brazilian VSB-30 sounding rockets supply the microgravity environment. The experiments are selected from universities and research institutes' proposals in response to an opportunity announcement (AEB 2012).

It should also be mentioned that there are plenty of new developments regarding the access and exploration of outer space in the ambit of both public and private initiatives (COPUOS 2015; Pyle 2019).

Owing to the harsh environmental conditions that space artifacts must endure and due to the unavailability of post-launch maintenance, the organization, development and management of space missions shall meet stringent programmatic and design requirements to guarantee that the mission will exhibit a fair chance of success.

Despite being more straightforward in technical terms and displaying much shorter mission times, it is still fundamental that sounding rocket missions be organized and executed within the formal framework of space missions, which is derived from the experience gathered in major space programs with the design, fabrication, integration, commissioning and operation of space systems. Formal space project management directives are organized into standards, such as those advocated by the European Cooperation for Space Standardization (ECSS) or those promoted by the National Aeronautics and Space Administration (NASA) (Blythe 2014).

In the present work, the organization and execution of sounding rocket missions, from the standpoint of the discipline of project management, are discussed first. It will then be shown that the development and implementation of a sounding rocket mission are organized in a sequence of phases very much akin to the project life-cycle advocated by the ECSS reference standard for space projects. Finally, as this article's main result, a reduced life-cycle is proposed, with corresponding processes and review meetings tailored to meet Brazilian sounding rocket missions' requirements, particularly those for the BMP.

The section "SOUNDING ROCKET MISSIONS AS PROJECTS" presents an overview of sounding rocket missions, along with arguments aimed at characterizing a sounding rocket mission as a project, and gives a brief introduction as to how space missions are organized from the standpoint of the ECSS standards. In the section "A PROPOSAL FOR THE LIFE-CYCLE OF A SOUNDING ROCKET MISSION", building on the definitions so far introduced, a mission life-cycle proposal tailored for sounding rocket missions in Brazil is given. The section "DISCUSSION" compares the proposed life cycle with those corresponding to ESA and NASA sounding rocket programs. Finally, the last section is dedicated to the conclusions.

\section{SOUNDING ROCKET MISSIONS AS PROJECTS}

Scientific and technological research since the late 1950s has been making use of sounding rockets. Initially conceived for meteorological and upper atmosphere research, the scope of sounding rocket missions has grown to encompass scientific investigations in areas such as fundamental physics, material science, fluid and combustion physics, and biology, as well as technical studies aimed at the testing and validation of innovative space equipment and subsystems, intended for future space applications 
(Kuhl et al. 2005; Seibert 2006). As an experimental platform, sounding rockets bring excellent advantages: they are unmanned, readily available and cost-effective (Kirchhartz et al. 2018).

Sounding rockets perform suborbital flights, following a parabolic trajectory, with a typical altitude range from hundreds to a thousand kilometers (Kirchhartz et al. 2018; NASA 2015). As shown in Fig. 1, they may reach altitudes even higher than those achieved by satellite launcher vehicles. An example of that is the Brazilian sounding rocket named VS-40, which can reach altitudes of $650 \mathrm{~km}$ carrying a $500 \mathrm{~kg}$ payload (IAE 2019).

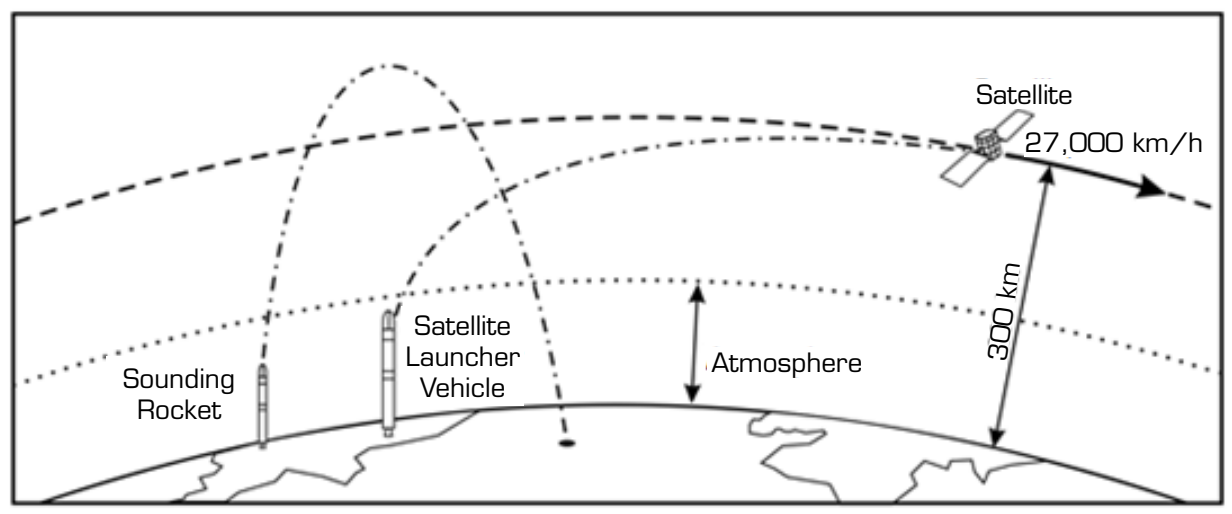

Figure 1. Schematic comparison between sounding rocket and launcher vehicle missions. Adapted from Pessoa Filho, Personal communication, 2014.

From a functional standpoint, a sounding rocket vehicle may be decomposed into three main parts: motor, with one or two stages, service system, with functions of control, telemetry and recovery and the payload system, where the experiments are installed, as illustrated in Fig.2, for the case of IAE's VSB-30 sounding rocket vehicle.

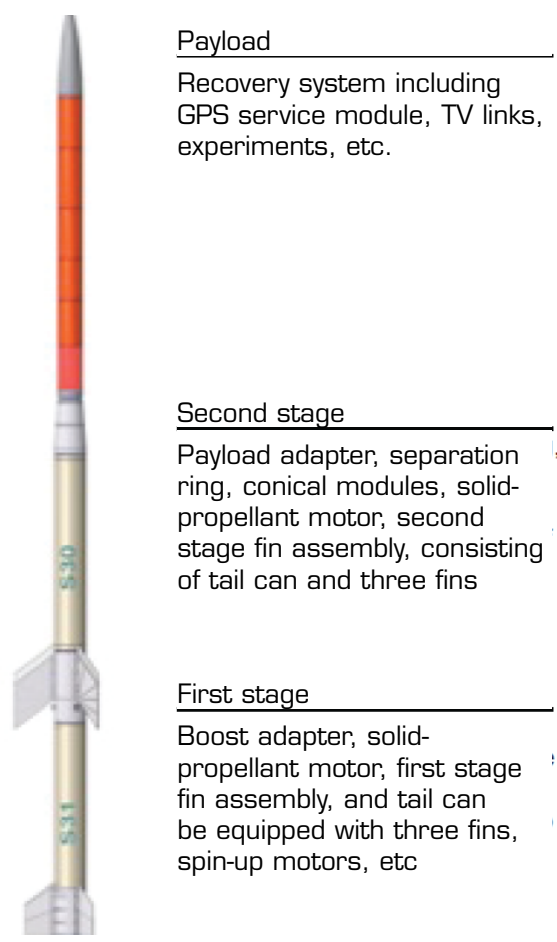

Figure 2. Schematic decomposition of a sounding rocket vehicle. Adapted from Garcia et al. (2011). 
Space projects start by eliciting requirements associated with either a need or an opportunity and proceed through various development stages up to the availability of the related products. In their turn, sounding rocket missions are equally defined by a set of requirements, which, if sufficiently well-defined, might guarantee that the designed system will meet the objectives of the mission and the criteria for its success.

Generally, the outcome of a space project is a system, which usually is composed of hardware, as a satellite and the launcher, facilities, as the control and mission centers, and personnel. The execution of a space project is carried out by an organization, which is commonly decomposed into segments. A natural decomposition encompasses the space, ground and application segments. In its turn, each segment is further decomposed into a segment work breakdown structure, which, in the case of the space segment, commonly follows the product tree associated with the satellite and the launcher. The ground and application segments may follow other decomposition logics. Fig. 3a gives an overview of a typical space project work breakdown structure (WBS).

A sounding rocket mission, in its turn, may be envisaged as composed of three segments. The application segment is responsible for the definition of the mission requirements and the use of the mission products, as well as for the development of the mission payloads. The launch segment is responsible for the sounding rocket vehicle, while the ground segment is responsible for the launching operations and the rescue operation of the payload. Fig. $3 \mathrm{~b}$ gives an overview of a typical sounding rocket mission WBS.

From this discussion and as depicted in Fig. 3, one sees that typical sounding rocket missions display an organization that is very much similar to that of usual space missions.

(a)

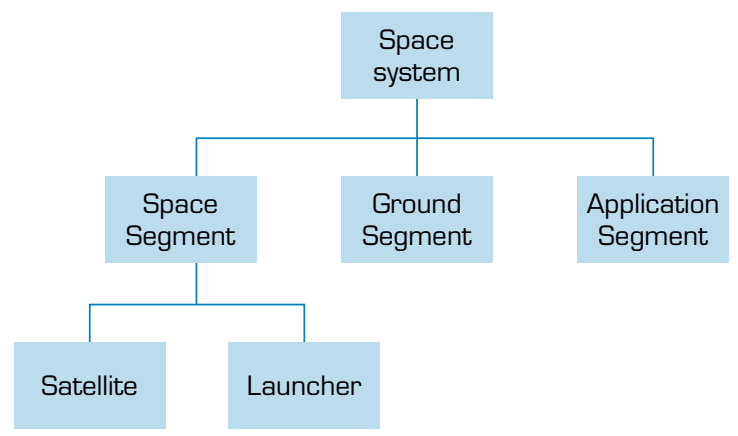

(b)

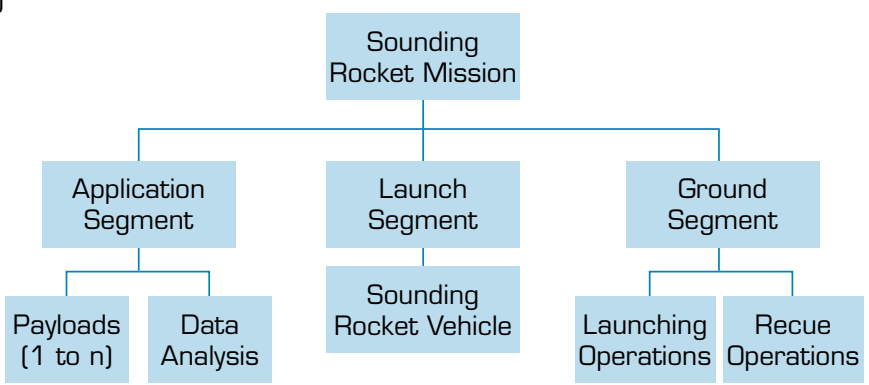

Figure 3. Typical work breakdown structure of a space project (a). Typical work breakdown structure of a sounding rocket mission (b).

A central concept in project management is that of the life-cycle of a project. Projects have a beginning and an end date, with their development taking place in a sequence of phases distributed along this time interval. The set of phases of a project is called the life-cycle of the project.

The transition from one project phase to another is marked by an end milestone, which takes the form of a project review meeting and is conducted by a special review board focused on examining the fulfillment of the objectives set forth for the phase. Identified nonconformities are subjected to an assessment that defines the way ahead regarding their disposition, which might comprehend since additional work for their complete solution, up to the acceptance of changes through the issuance of waivers. Once all nonconformities are successfully disposed of, the project team is authorized to move forward to the next life-cycle phase. 
The definition, number and scope of phases in the life-cycle of a project may vary from one industrial sector to another. Different organizations commend different approaches for the life-cycle of projects in the space sector, those from NASA and ECSS being the primary references.

The life-cycle of projects undertaken in the Brazilian space program, mainly as far as INPE is concerned, typically follows the ECSS standard. The project life-cycle commended by the ECSS standard for space projects is schematically shown in Table 1.

Table 1. Life-cycle for a space mission as preconized by the ECSS standard.

\begin{tabular}{|c|c|}
\hline Phase & Description \\
\hline $\begin{array}{l}\text { O: Mission analysis/ } \\
\text { identification of needs }\end{array}$ & $\begin{array}{l}\text { Elaborate the mission statement with the identification and characterization of the } \\
\text { mission needs and expected performance. } \\
\text { Develop the preliminary technical requirements specification. } \\
\text { Identify possible mission concepts. } \\
\text { Perform preliminary risk assessment. }\end{array}$ \\
\hline A: Feasibility & $\begin{array}{l}\text { Elaborate possible system and operations concepts and system architectures and compare } \\
\text { these against the identified needs. } \\
\text { Assess the technical and programmatic feasibility of the possible concepts by identifying } \\
\text { constraints relating to implementation, costs, schedules, organization, operations, } \\
\text { maintenance, production and disposal. } \\
\text { Identify critical technologies and propose pre-development activities. } \\
\text { Propose the system and operations concept(s) and technical solutions, including model } \\
\text { philosophy and verification approach, to be further elaborated during phase B. } \\
\text { Elaborate the risk assessment. }\end{array}$ \\
\hline B: Preliminary definition & $\begin{array}{l}\text { Finalize the project management, engineering and product assurance plans. } \\
\text { Establish the baseline master schedule. } \\
\text { Elaborate the baseline cost at completion. } \\
\text { Elaborate the preliminary organizational breakdown structure (OBS). } \\
\text { Confirm technical solution(s) for the system and operations concept(s) and their feasibility with } \\
\text { respect to programmatic constraints. } \\
\text { Conduct "trade-off" studies and select the preferred system concept, along with the } \\
\text { preferred technical solution(s) for this concept. } \\
\text { Establish a preliminary design definition for the selected system concept and retained } \\
\text { technical solution(s). } \\
\text { Determine the verification program including model philosophy. } \\
\text { Prepare the next level specification and related business agreement documents. } \\
\text { Initiate pre-development work on critical technologies or system design areas when it is } \\
\text { necessary to reduce the development risks. } \\
\text { Conduct reliability and safety assessment. } \\
\text { Finalize the product tree, the work breakdown structure and the specification tree. } \\
\text { Update the risk assessment. }\end{array}$ \\
\hline C: Detailed definition & $\begin{array}{l}\text { Completion of the detailed design definition of the system at all levels in the customer-supplier } \\
\text { chain. } \\
\text { Production, development testing and pre-qualification of selected critical elements and } \\
\text { components. } \\
\text { Production and development testing of engineering models, as required by the selected } \\
\text { model philosophy and verification approach. } \\
\text { Completion of assembly, integration and test planning for the system and its constituent } \\
\text { parts. } \\
\text { Detailed definition of internal and external interfaces. } \\
\text { Update of the risk assessment. }\end{array}$ \\
\hline $\begin{array}{l}\text { D: Qualification and } \\
\text { production }\end{array}$ & $\begin{array}{l}\text { Complete qualification testing and associated verification activities. } \\
\text { Complete manufacturing, assembly and testing of flight hardware/software and } \\
\text { associated ground support hardware/software. } \\
\text { Complete the interoperability testing between the space and ground segment. } \\
\text { Prepare acceptance data package. }\end{array}$ \\
\hline E: Operations/utilization & $\begin{array}{l}\text { Perform all activities at the space and ground segment level in order to prepare the launch. } \\
\text { Conduct all launch and early orbital operations. } \\
\text { Perform on-orbit verification (including commissioning) activities. } \\
\text { Perform all on-orbit operations in order to achieve the mission objectives. } \\
\text { Perform all ground segment activities in order to support the mission. } \\
\text { Perform all other ground support activities in order to support the mission. } \\
\text { Finalize the disposal plan. }\end{array}$ \\
\hline F: Disposal & Implement the disposal plan. \\
\hline
\end{tabular}


There are a total of seven phases, covering the whole life-cycle of the system. The eliciting of requirements takes place in phase 0 , while the proposal of architectures, the assessment of their feasibility and the selection of one of them are carried out either in phase A or, at most, at the beginning of phase B. The preliminary and detailed design of all system components belonging to the chosen architecture takes place in phases $\mathrm{B}$ and $\mathrm{C}$, while the manufacturing, integration and verification of the flight specimens and the system takes place in phase D. The launching and commissioning of the system is carried out in phase E. Finally, the decommissioning and disposal of the system occurs in phase F. Table 1 summarizes each phase.

Next, a brief description of what might be interpreted as the main elements of the life cycle of a sounding rocket mission is given. A sounding rocket mission is, in principle, defined by a set of requirements that establishes an architecture for the mission, comprising the payload, the vehicle and the ground segment.

Once defined the architecture, the mission advances to its implementation phase, when the payload, the vehicle and the ground segment are designed, manufactured, verified and integrated. Finally, all elements are made available at the launching site for payload integration and launching. Following a successful launching campaign, the operational phase begins with the processing of the generated data and the availability of the products. Finally, eventual disposal actions are carried out during the decommissioning phase.

From this discussion, one sees that a typical sounding rocket mission, besides presenting similar organization as that of a space project, also follows a life-cycle very much akin to that of a project in the space area, in which system elements are defined from mission requirements and are designed, manufactured and integrated sequentially, with verifications at the end of each stage.

Depending on the characteristics of the project, mainly as regards the level of recurrence of leading tasks and the nature of its deliverables, whether tangible, not tangible, or a mix of both, a special life-cycle might be tailored, simplifying the canonical life-cycle commended by standards, while keeping its essence as regards the management of scope, time, cost and reliability.

As the result of a scrutiny of the literature, one may assert that detailed conceptual management frameworks for sounding rocket missions have not been addressed so far. In the next section, a proposal for a reduced life-cycle for developing projects associated with sounding rocket missions, based on the ECSS standard, tailored to meet Brazilian sounding rocket missions, is presented and discussed.

\section{A PROPOSAL FOR THE LIFE-CYCLE OF A SOUNDING ROCKET MISSION}

As stressed in section "SOUNDING ROCKET MISSIONS AS PROJECTS”, the architecture for a sounding rocket mission does not change in its essence from one mission to another, comprising, essentially, the application, launch and ground segments, the latter encompassing a great deal of tasks, from launching operations to the availability of mission products.

Although displaying all the elements of a typical satellite mission, sounding rocket missions involve substantially smaller scope and reduced complexity in all segments. For instance, as far as the payload is concerned, in most situations, one finds a suborbital platform equipped with rather simple equipment instead of a whole satellite system. One finds a well-defined and relatively simple vehicle from the outset, instead of a very much evolved satellite launcher and complex orbiting operations. Finally, as regards the ground segment, one finds very much simplified infrastructure and ground operations. For instance, the operational phase of a sounding rocket mission typically takes hours rather than years, as in conventional satellite missions.

This study attempts to make explicit these simplifications, segment by segment, since such approximations constitute the basis for the proposal of a reduced project life-cycle for sounding rocket missions, presented later in this section.

As regards the mission payload segment, it is seen that the geometric, electrical and mechanical requirements for the mission payload are well defined from the outset, mostly given by the chosen mission sounding rocket vehicle, greatly simplifying the whole payload development life-cycle. Despite this simplification, a great deal of effort has still to be put into the definition of the scientific and technological experiments, which will be realized during the mission and to guarantee that the mission requirements are elicited. For instance, for each experiment, the scientific or technological questions expected to be answered by the experiment shall be clearly stated, and it shall be demonstrated that the proposed parameters for the mission, such as the trajectory or maximum altitude of the vehicle, are compatible with the experiments' objectives. Considerable effort goes into the definition of the architecture of each experiment and the mission as a whole. When dealing with a series of sequential 
missions in a program, as in a microgravity program, lessons learned from previous missions might further improve the payload development effort.

Concerning the vehicle segment, the vehicle's general characteristics, in typical situations, are defined before the definition of the mission. Only in extraordinary circumstances will there be a complete cycle of development of the vehicle, ranging from project to manufacturing and testing.

In this way, the tasks associated with the vehicle might be grouped in a single phase. Mostly, there will be no changes in the first and second stages, while only relatively small adaptations to accommodate the mission payload might take place in the payload stage (see section SOUNDING ROCKET MISSIONS AS PROJECTS).

Finally, as regards the ground segment, some straightforward simplifications might also be introduced. In a sounding rocket mission, the tasks associated with launching, operation of the system, and disposal might be undertaken in the same phase. Phasing out activities (ECSS 2012) are greatly simplified since no space debris are left. There is no need to plan for a decommissioning phase of the system, although concern with the disposal of the parts that return to Earth and their eventual recovery should remain.

Considering both the information presented so far and the ECSS reference standard, as well as the simplifications discussed above, the proposed life-cycle phases for the project associated with sounding rocket missions, adapted to Brazilian programs, is given in Table 2, which also shows the proposed review meetings associated with each phase.

Table 2. Proposed life-cycle for a sounding rocket mission, adapted to Brazilian programs.

\begin{tabular}{|c|c|c|c|c|c|}
\hline Phases & Phase 0 & Phase A & Phase B/C & Phase D & Phase E/F \\
\hline & Mission analysis & Feasibility & Design & $\begin{array}{l}\text { Manufacturing, } \\
\text { assembly, } \\
\text { integration and } \\
\text { testing }\end{array}$ & $\begin{array}{l}\text { Launching and } \\
\text { mission closeout }\end{array}$ \\
\hline Reviews & $\begin{array}{l}\text { MDR (mission } \\
\text { design review) }\end{array}$ & $\begin{array}{l}\text { PRR (preliminary } \\
\text { requirements } \\
\text { review) }\end{array}$ & $\begin{array}{c}\mathrm{DR} \\
\text { [design review] }\end{array}$ & $\begin{array}{c}\text { QR (qualification } \\
\text { review) } \\
\text { SIR (system } \\
\text { integration review) } \\
\text { AR (acceptance } \\
\text { review) } \\
\text { ORR (operational } \\
\text { readiness review) }\end{array}$ & $\begin{array}{c}\text { FRR (flight } \\
\text { readiness review) } \\
\text { PFAR (post-flight } \\
\text { analysis review) } \\
\text { MCR (mission } \\
\text { closeout review) }\end{array}$ \\
\hline
\end{tabular}

Given the similarities pointed out between sounding rocket missions and typical space projects, one would naturally expect some affinity between life-cycle phases. Table 3 presents a comparison of the proposed life-cycle for a sounding rocket mission with that preconized by the ECSS standard, including a comparison of the review meetings. The main differences concern the design phases and the operational and disposal phases.

Table 3. Comparison of proposed life-cycle for a sounding rocket mission with that preconized by the ECSS standard.

\begin{tabular}{|c|c|c|c|c|c|}
\hline \multicolumn{3}{|c|}{ ECSS } & \multicolumn{3}{|c|}{ BMP } \\
\hline Phases & Description & Reviews & Phases & Description & Reviews \\
\hline 0 & Mission analysis & MDR & 0 & Mission analysis & MDR \\
\hline$A$ & Feasibility & PRR & $A$ & Feasibility & PRR \\
\hline $\mathrm{B}$ & Preliminary definition & SRR, PDR & \multirow{2}{*}{$B / C$} & \multirow{2}{*}{ Design } & \multirow{2}{*}{$\mathrm{DR}$} \\
\hline C & Detailed definition & CDR & & & \\
\hline $\mathrm{D}$ & Qualification and production & $\mathrm{QR}, \mathrm{AR}, \mathrm{ORR}$ & $\mathrm{D}$ & $\begin{array}{l}\text { Manufacturing, assembly, } \\
\text { integration and test }\end{array}$ & $\begin{array}{c}\text { QR, SIR, AR, } \\
\text { ORR }\end{array}$ \\
\hline$E$ & Operations & FRR, LRR, CRR, ELR & \multirow{2}{*}{$E / F$} & \multirow{2}{*}{ Launching and closeout } & \multirow{2}{*}{$\begin{array}{c}\text { FRR, PFAR, } \\
\text { MCR }\end{array}$} \\
\hline $\mathrm{F}$ & Disposal & MCR & & & \\
\hline
\end{tabular}


The justification for the joining of the operational and disposal phases has already been given. The design phases, phases B and $\mathrm{C}$, are proposed to be amalgamated into a single phase. Requirements for sounding rocket experiments involve only the environment associated with the launcher, without the necessity of provisions regarding operation in vacuum and operation under radiation, thermal stress, or atomic hydrogen. This noticeable reduction in requirements breadth greatly simplifies the selection of parts and materials and the design verification, which, in most circumstances, might be carried out under an engineering and qualification model philosophy (ECSS 2012). It should also be noted that the operational lifetime of payload equipment in sounding rocket missions is only a fraction of what is typical for space missions, which also greatly simplifies the design.

To complete the proposal articulated in this article, a brief description of the scope and goals of each phase and associated review meetings is given below. Note that the primary purpose of this paper is to provide a tailoring of the ECSS standard to sounding rocket missions concerning system engineering and project management. The following description attempts to detail, phase by phase, the specializations of the ECSS standard in constructing the proposed life-cycle. Along with the description of the ECSS standard given in section SOUNDING ROCKET MISSIONS AS PROJECTS, summarized in Table 1, and detailed comparisons given in Tables 2 and 3, the description given below shows, with detail, the tailoring of the ECSS standard to the present finality.

\section{Phase 0 - mission analysis}

This phase, like ECSS phase 0, aims to gather accurate information about the mission objectives and technical characteristics. The data thus collected and structured are translated into requirements for the mission. This phase's primary outcome is the mission statement, containing the identification and characterization of the mission needs and a description of the mission constraints regarding the physical and operational environment.

The main topics to be addressed are as follows:

- General: Sounding rocket clients must provide detailed information about their experiments' needs, such as power, volume and geometry, mass and other specific requirements;

- Mechanical devices: Statement of the need to develop and install mechanical devices on the payload, such as an ejectable nose cone, access windows to the experiment, sensor positioning, antenna installation requirements and any other structural requirements shall be provided;

- Vehicle performance requirements: Encompass the presentation of the performance requirements expected by the experiments, such as apogee altitude, microgravity time, spin rates, trajectory, launch time, temperature limits, vibration and other aspects of performance essential for the accomplishment of scientific or technological research. After each experiment's needs are presented, the project team identifies possible vehicle alternatives to execute the mission and shows them at phase A;

- Instrumentation: Clients should be able to provide information about the need for the installation of transducers in the vehicle and the acquisition rates.

The associated review meeting that defines whether the project has met the planned scope is the mission definition review (MDR).

The MDR has as primary goals the review and approval of the mission statement and the assessment of the preliminary technical requirements specification. The essential topics covered in the meeting are given below.

- During MDR, sounding rocket clients must be prepared to review the information about their experiments' needs, which should be as complete and precise as possible;

- Programmatic requirements and restrictions shall be reviewed in the meeting.

Essential phase 0 outcomes are as follows:

- Preliminary technical requirements specification;

- Preliminary mission concepts;

- Preliminary risk assessment.

\section{Phase A - feasibility}

Having as preliminary input proposals of mission architecture and the mission technical and environmental requirements, phase A has as its primary goals the proposition of both a system architecture and an operations concept, including, for more evolved missions, a philosophy for engineering and qualification models and a verification approach (ECSS-M-ST-10C). 
The feasibility of the proposed system and operations concept shall be assessed concerning primary mission goals and technology, technical personnel, schedule, costs, infrastructure and other variables that are deemed relevant.

The main topics to be addressed are as follows:

- Specify the technical requirements;

- Confirm the technical feasibility of the proposed solutions, mainly regarding the architecture and the concept of operations;

- Define the model philosophy and the verification approach to be adopted;

- Present the preliminary schedule, including the main milestones in the project development as dates of the project review meetings, delivery dates, dates of equipment tests, dates to assemble, integrate and test the payload with the experiments and dates of the shipment to the launch site;

- Present performance parameters for each vehicle solution, such as apogee, microgravity time, spin rates, temperature limits, vibration and other performance parameters deemed necessary for scientific or technical research;

- Define feasible solutions for installing sensors in the vehicle, acquisition rates and the possibility of installing timers and telecommand receivers for the experiments;

- Specify the tests to which the experiments and the integrated payload will be submitted;

- Prepare a WBS based on the information provided by the involved parties up to work packages' level and define the personnel responsible for each management instance of the WBS.

The associated review meeting is termed the preliminary requirements review (PRR). In the PRR meeting, the system and operations concept(s) developed and studied in phase A are presented and assessed. The chosen concepts for the system and operations shall be justified.

Essential topics covered in the meeting are as given below:

- Releasing of preliminary management, engineering and product assurance plans;

- Releasing of the technical requirements specification;

- Confirmation of the technical feasibility of the proposed solutions;

- Selection of the system and operations concept and technical solutions, including the model philosophy and the verification approach. Essential phase A outcomes are as follows:

- Preliminary management, engineering and product assurance plans;

- Technical requirements specification;

- System and operations concepts;

- Updated risk assessment.

\section{Phase $B / C$ - design}

During phase $\mathrm{B} / \mathrm{C}$, the information on requirements, constraints and specifications must be sufficiently detailed so that the design of both the payload equipment and the interface payload subsystem/launcher, as well as the ground system, can proceed up to their completion and verification.

The main topics to be addressed are as follows:

- Allocate requirements for equipment and subsystems, for the interface space segment/launcher and the ground segment;

- Conduct cost-benefit and technology maturity studies;

- Establish metrics for the choice of solutions;

- Elaborate on the design of the payload equipment and the payload/vehicle interface;

- Elaborate on the design of the ground segment;

- Develop test plans for both equipment and payload subsystems;

- Update the management plan and risk assessment.

The associated review meeting is termed the design review (DR). The DR main goal is the approval of the design of the selected system and operations concepts. Technical solutions shall be implemented against project and system requirements.

Essential topics covered in the meeting are as follows: 
- The design review shall issue an assessment regarding the design of each equipment and the payload, and the adopted solutions shall be justified;

- It shall be demonstrated that the project has a significant chance of achieving the proposed objectives and reliably, at an acceptable cost and within the established schedule;

- Detailed test plans for equipment, subsystems and integrated systems shall be presented;

- Reviews of high-risk procedures, such as vehicle activation and pressurizing systems, shall be given;

- New methods and processes of manufacturing and operation shall be assessed and approved.

Essential phase $\mathrm{B} / \mathrm{C}$ outcomes are as follows:

- Design of the payload equipment;

- Design of the interface payload subsystem/launcher;

- Design of the ground system;

- Updated risk assessment.

\section{Phase D - manufacturing, assembly, integration and testing}

In this phase, with the design already approved, the manufacturing, integration and verification of the different models are accomplished. The main topics to be addressed are given below and organized according to the corresponding system element and verification tests. Payload manufacturing and pre-integration tests:

- The purchased electronic equipment, along with those produced in-house, shall be available for pre-integration testing;

- Newly developed equipment must be subjected to qualification tests to ensure that their part, materials and manufacturing processes are robust enough to attend mission requirements.

Payload integration and tests:

- Payload equipment, along with their interface, shall be integrated and tested in the flight configuration for the verification of payload compatibility and payload and interface compatibility;

- Both functional and acceptance tests shall be performed.

Acceptance tests:

- After completing functional tests, the integrated payload shall be subjected to acceptance tests, where flight conditions will be simulated for assessing the operational status of the payload; the payload shall have all its subsystems operational;

- Once the acceptance tests are completed, the payload must again be subjected to functional tests and inspections to verify that all systems remain in sufficiently good condition to be taken to the launch site;

- At the end of these tests, the results must be presented in an acceptance review (AR), where these results are analyzed and it is verified if the system is ready to proceed to the next phase.

Operational readiness:

- After completion of the acceptance tests, the operational readiness review (ORR) should be held, where the results of the tests and the equipment readiness for shipment to the launch site are verified.

This phase has three associated review meetings. The first one is the system integration review (SIR), with a quite self-descriptive scope. The second is the AR and is held just before delivering the project products for the launching phase, while the third is the ORR, which is held just before the transport of the system to the launch center.

Prior to the integration activities, concerning payload and sounding rocket systems, the vehicle and payload's equipment and devices shall be subjected to inspections and functional tests.

The SIR meeting is held before the beginning of payload/sounding rocket integration activities. Essential topics covered in the meeting are as follows:

- Present the final plans and procedures for assembly, integration and testing;

- Analyze the results of functional tests and inspections, as well as qualification tests, when applicable;

- Ensure that any discrepancies found in the project reviews have been resolved;

- Verify that all teams, equipment and facilities are ready to proceed to the assembly, integration and testing of experiments with the payload and vehicle; 
- Issue the authorization for the integration of the payload with the sounding rocket systems.

After integration, all equipment and systems are installed in the flight configuration and shall then be submitted to acceptance tests, which are intended to prove that the integrated systems and subsystems attend the mission's requirements.

The AR meeting is held after the finalization of payload/sounding rocket integration activities, reviewed in this meeting. Important topics covered are as follows:

- Check compliance with requirements, with margins;

- Examine the verification records to make sure they are complete;

- Evaluate acceptance test results;

- Publish the acceptance certificate of the integrated payload.

Finished the tests, the ORR is held, where the tests' results and the equipment readiness for shipment to the launch site are verified. The ORR aims to determine if all systems, personnel and launch site are ready to proceed to the launching activities. At ORR, the following topics are addressed:

- The test results of the integrated payload;

- The readiness of the launching site;

- The licenses to conduct the mission;

- Non-conformities found at the assembling, integration and tests phase, and implemented solutions;

- Managerial and operational procedures;

- Issuing of the authorization for shipment to the launch site. The most relevant outcomes of phase $\mathrm{D}$ are as follows:

- Flight model of the payload;

- Flight model of the sounding rocket;

- Flight model of the interface payload/sounding rocket;

- Integrated payload/sounding rocket subsystem ready for flight;

- System, subsystems, personnel, and launch site prepared for the launching event.

\section{Phase E/F - launching and mission closeout}

In this phase, the launch of the sounding rocket occurs and the in-flight experiments are carried out. The mission products are made available to the application segment and mission closeout activities are carried out.

The associated reviews of this phase are the FRR, PFAR, and MCR.

The main topics addressed in this phase are as follows:

- As pre-launching activities and just before the launching event, the whole system, involving sounding rocket, integrated payload, ground field systems and personnel should be readied for the launching and flight operations;

- As post-launching activities, the issuance of a preliminary flight analysis and the development of closeout activities are carried out. The first associated review is the FRR. In this review, all involved personnel must demonstrate that they are ready for the flight. Functional tests, as well as those carried out within the launching field system, should be evaluated, making sure that the rocket can proceed for the launching at an acceptable risk.

Essential topics covered in the meeting are as follows:

- It should be demonstrated that all systems are in the launching configuration;

- The final assembly procedures of the payload integrated in the launcher and the launching operations shall be carefully reviewed, confirming the system readiness state for the launching operations.

The objective of the PFAR is to evaluate if all the activities planned for the flight, until its recovery, occurred as expected. All the anomalies identified are used in the lessons learned process to mitigate or eliminate the corresponding problems for future flights. The essential topics covered in this review are as follows:

- Assessment of all anomalies;

- Assessment on the overall post-recovery condition;

- Photos and videos availability; 
- Disassembly plans and schedule;

- Evaluation of the preliminary flight data.

The last associated review is the MCR. Among the topics covered in the meeting, the ones listed below are essential:

- Provide a detailed report of the results of the experiments;

- Evaluate the performance of the teams involved, based on detailed reports from each team;

- Provide a report about the disposal of the system elements;

- Provide a report about the documenting of lessons learned for use in future missions;

- Provide a report about mission safety and risk management.

The most relevant phase $\mathrm{E} / \mathrm{F}$ outcomes are as follows:

- Availability of mission products;

- Report about mission performance and results;

- Disposal of system elements;

- Lessons learned for future missions.

\section{DISCUSSION}

\section{Comparison with other sounding rocket programs}

In this section, the sounding rocket campaign life-cycle proposed in this article is compared with those commended for ESA and NASA sounding rocket programs. The proposal given here has been formulated taking as a reference the BMP, sponsored by AEB, with sounding rocket campaigns executed from two launching sites: the Centro de Lançamento Barreira do Inferno (CLBI), located in Rio Grande do Norte, and the Centro de Lançamento Alcântara (CLA), situated in Maranhão. The mission life-cycle of a typical BMP mission is given in Fig. 4.

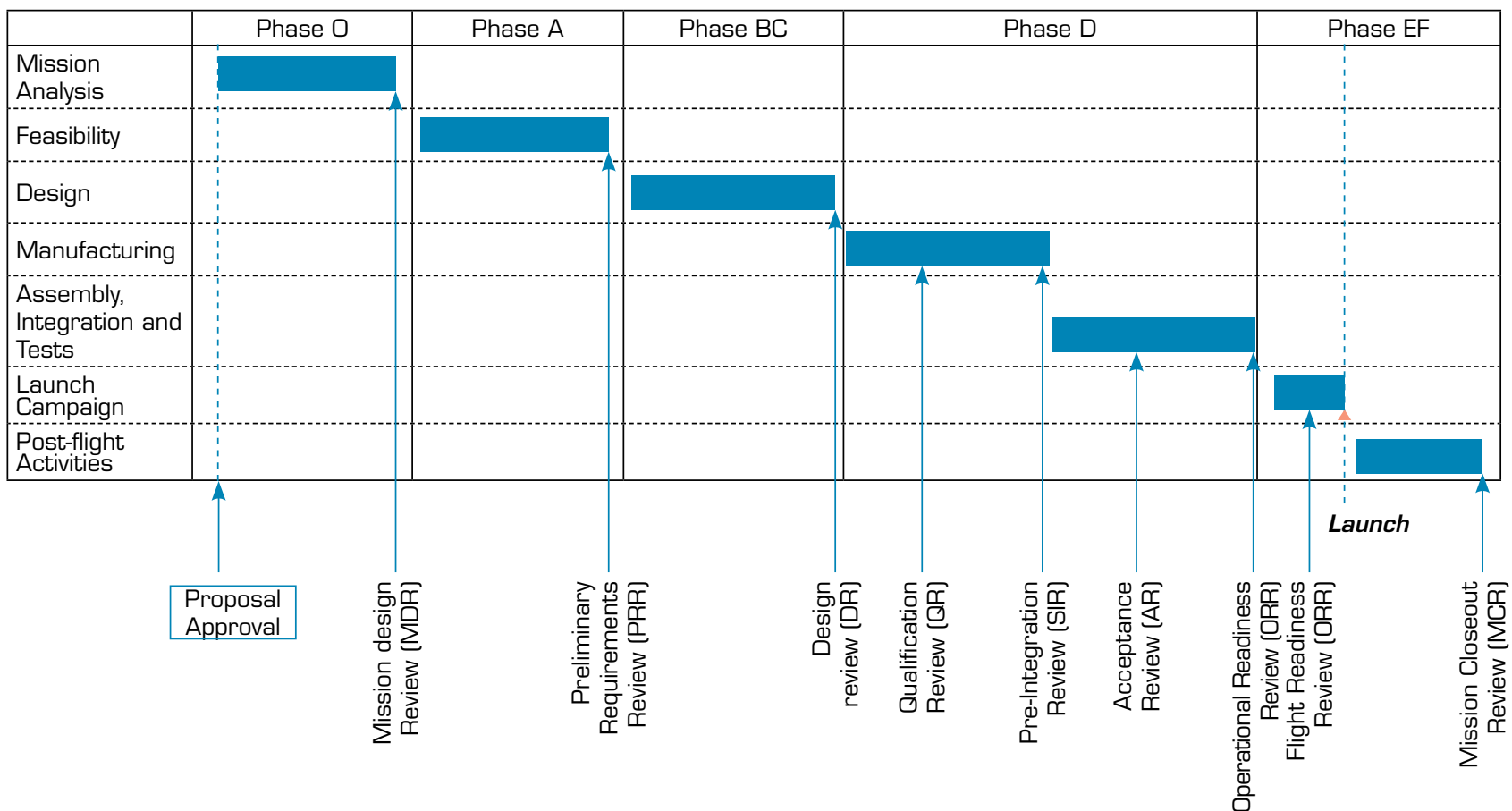

Figure 4. Proposed life-cycle for sounding rocket missions from the BMP program. 
The European Programme for Life and Physical Sciences in Space (ELIPS), sponsored by ESA, provides access to microgravity environment through such platforms as drop towers, parabolic flights, sounding rockets, retrievable orbital capsules and the International Space Station (ISS) (Wilson 2012). The sounding rocket campaigns from this program are deployed from the Esrange Launching Center in Sweden (Sabbatini 2014).

Figure 5 reproduces a typical schedule for a launching campaign from the ELIPS program given by Sabbatini (2014).

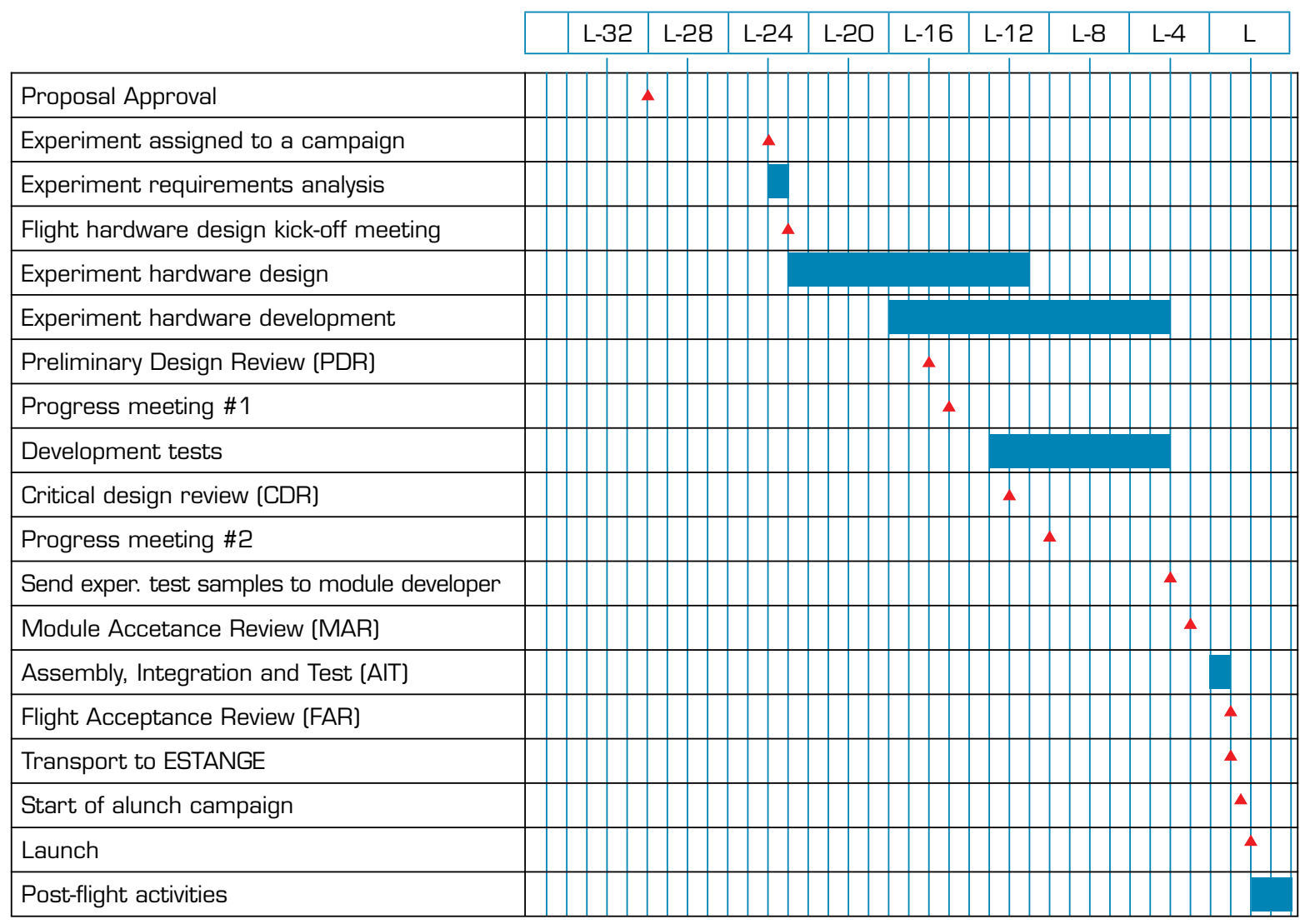

Figure 5. Typical timeline for an experiment on a sounding rocket flight campaign from the ELIPS program. Source: Reproduced from Sabbatini (2014).

Considering the life-cycle commended by the ECSS standard as a reference and taking into account the tasks and the review meetings identified in Fig. 5, this research attempted to construct the mission life-cycle for a typical ELIPS mission. The result is shown in Fig. 6. The following assumptions were made in this derivation: (a) since there is no indicative milestone separating phase 0 from phase A, both phases were considered amalgamated; (b) the milestone Flight Hardware Kick-off meeting, coincident with the beginning of the task Experiment Hardware Design, has been taken as the final of phase A, coincident with the start of phase B; (c) the milestone preliminary design review (PDR) meeting has been taken as marking the final of Phase B, following the ECSS reference; (d) the milestone critical design review (CDR) meeting has been taken as marking the closing of phase $C$, in agreement with the ECSS reference; (e) the milestone flight acceptance review AR meeting, which takes place at the end of the task Assembly Integration and Tests (AIT), has been considered as signalizing the final of phase D; (f) although no review meeting associated with the start of the launching campaign was indicated in Fig. 5, the existence of a review meeting associated with this milestone was assumed and referred to by the acronym SLC (start of launching campaign); (g) since there is no indicative milestone separating phase E from phase F, both phases were considered amalgamated; (h) since the schedule does not show a 
review meeting associated to the closeout of the mission, the mission finalization activities were assumed to be carried out independently, possibly at a segment level.

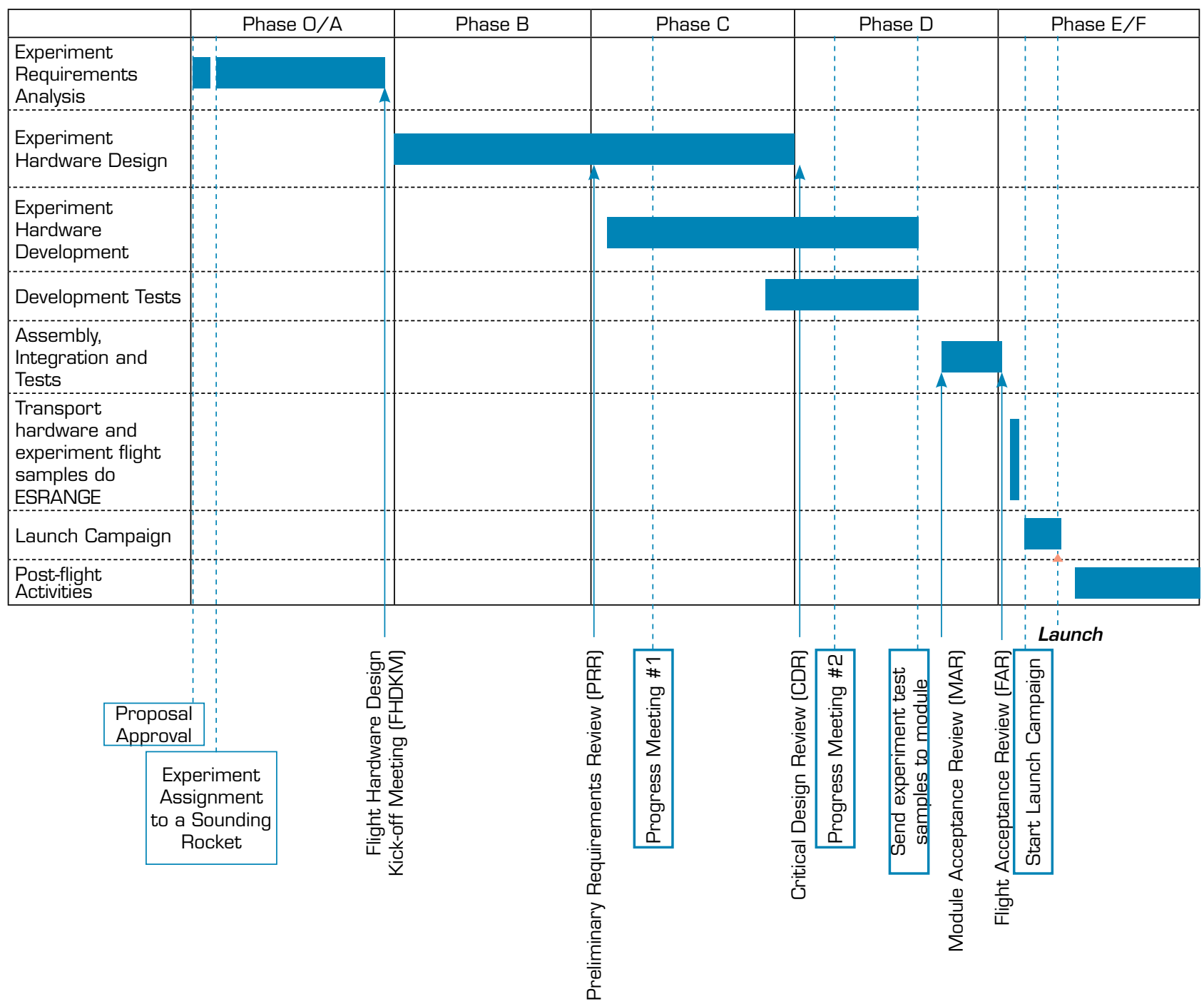

Figure 6. Life-cycle for sounding rocket missions from the ESA ELIPS program, as inferred from the mission schedule given in Fig. 5.

The NASA sounding rocket program (NSRP), sponsored by NASA, is a “... suborbital space flight program that primarily supports NASA-sponsored space and earth sciences research activities, other government agencies, and international sounding rocket groups and scientists ...” and is executed by NASA's Suborbital and Special Orbital Projects Directorate (SSPOD) (NASA Goddard Space Flight Center, 2015). The NSRP campaigns are developed through the facilities of the Wallops Flight Facility of the Goddard Space Flight Center. Figure 7 reproduces a typical NSRP mission life-cycle after SSPOD.

Considering the life-cycle preconized by the ECSS standard as a model and taking into consideration the life-cycle scheme given in Fig.7, as well as further information given in the corresponding reference, the mission life-cycle of a typical NSRP mission acquires the form shown in Fig. 8. Table 4 compares the mission/campaign life-cycles from the BMP, the ELIPS and the NSRP programs. 


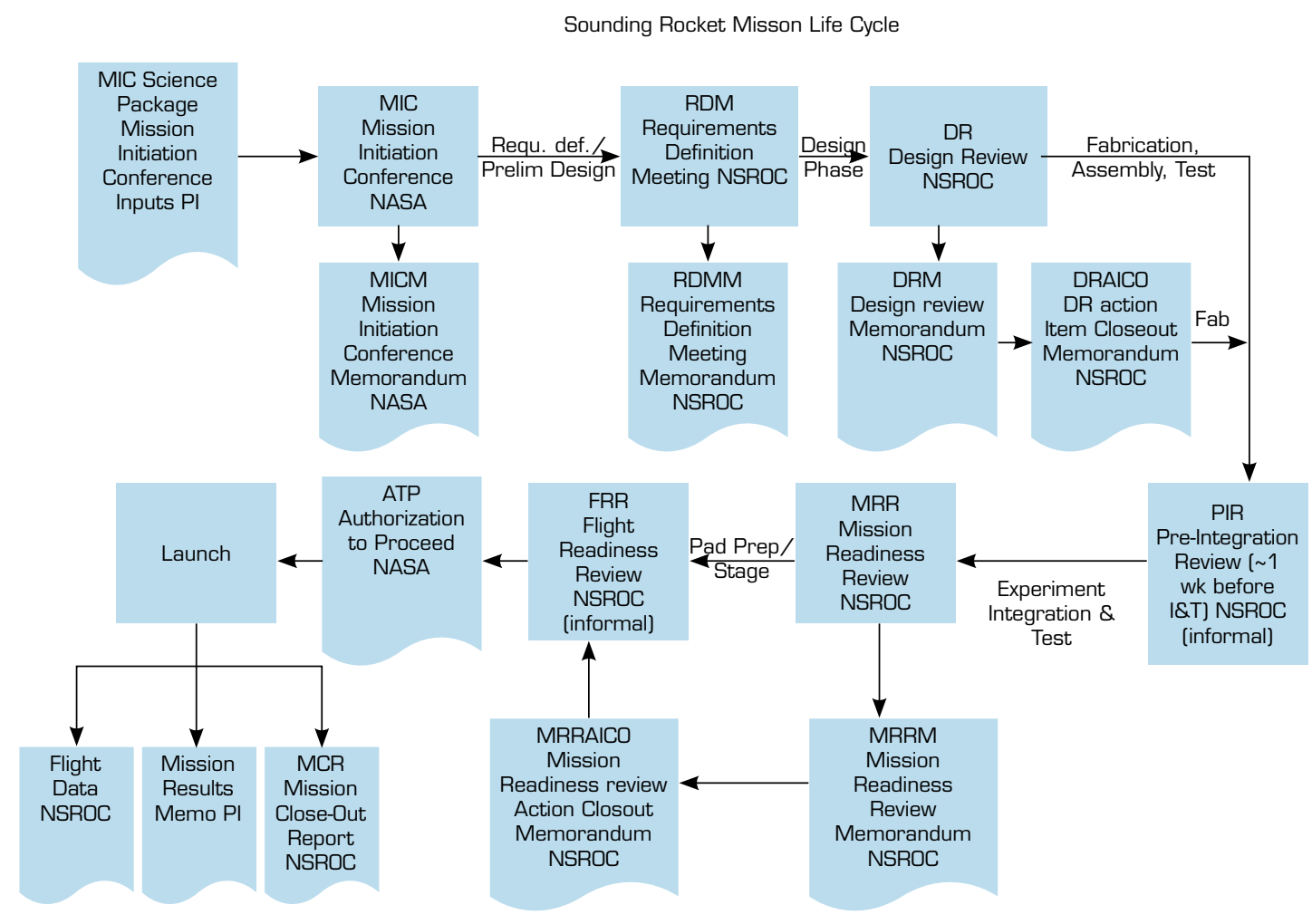

Figure 7. Typical life-cycle for an experiment on a sounding rocket flight campaign from the NASA sounding rocket program. Source: Reproduced from (NASA Goddard Space Flight Center, 2015).

\begin{tabular}{|c|c|c|c|c|c|c|}
\hline & Phase 0/A & Phase B/C & Phase D & & \multicolumn{2}{|l|}{ Phase EF } \\
\hline $\begin{array}{l}\text { Requirements } \\
\text { Definition }\end{array}$ & & & & & & \\
\hline Design Phase & & & & & & \\
\hline $\begin{array}{l}\text { Payload } \\
\text { Fabrication and } \\
\text { Pre-integration } \\
\text { Testing }\end{array}$ & & & & & & \\
\hline $\begin{array}{l}\text { Integration and } \\
\text { Testing }\end{array}$ & & & & & & \\
\hline $\begin{array}{l}\text { Launch } \\
\text { Operations }\end{array}$ & & & & & & \\
\hline $\begin{array}{l}\text { Mission } \\
\text { Closeout }\end{array}$ & & & & & & \\
\hline 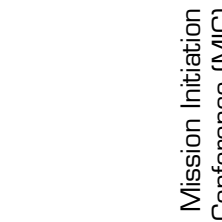 & 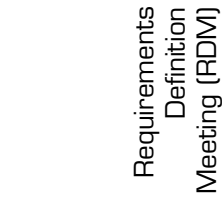 & 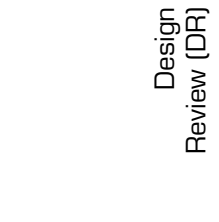 & 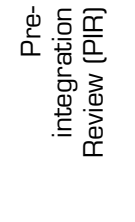 & 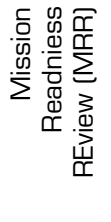 & 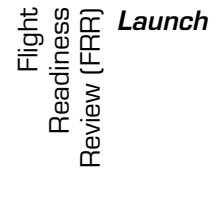 & 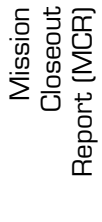 \\
\hline
\end{tabular}

Figure 8. Life-cycle for sounding rocket missions from the NSRP program, as inferred from the mission schedule given in Fig. 7. 
Table 4. Comparison of sounding rocket mission life-cycles corresponding to the BMP, NSRP and ELIPS programs. The reader is referred to Figs. 4,6 and 8 for the meaning of the review meeting acronyms.

\begin{tabular}{|c|c|c|c|c|c|c|c|c|}
\hline \multicolumn{3}{|c|}{ BMP } & \multicolumn{3}{|c|}{ ELIPS } & \multicolumn{3}{|c|}{ NSRP } \\
\hline Phases & Description & Reviews & Phases & Description & Reviews & Phases & Description & Reviews \\
\hline 0 & Mission analysis & MDR & \multirow{2}{*}{ O/A } & \multirow{2}{*}{$\begin{array}{l}\text { Mission analysis } \\
\text { and feasibility }\end{array}$} & \multirow{2}{*}{ FHDKM } & \multirow{2}{*}{ O/A } & \multirow{2}{*}{$\begin{array}{l}\text { Requirements } \\
\text { definition }\end{array}$} & \multirow{2}{*}{$\begin{array}{l}\text { MIC } \\
\text { RDM }\end{array}$} \\
\hline$A$ & Feasibility & PRR & & & & & & \\
\hline \multirow{2}{*}{$\mathrm{BC}$} & \multirow{2}{*}{ Design } & \multirow{2}{*}{$\mathrm{DR}$} & $\mathrm{B}$ & $\begin{array}{l}\text { Preliminary } \\
\text { design }\end{array}$ & PDR & \multirow{2}{*}{$B / C$} & \multirow{2}{*}{ Design phase } & \multirow{2}{*}{$\mathrm{DR}$} \\
\hline & & & C & $\begin{array}{l}\text { Detailed } \\
\text { design }\end{array}$ & $\begin{array}{l}\text { PM\#1 } \\
\text { CDR }\end{array}$ & & & \\
\hline \multirow[t]{2}{*}{$D$} & \multirow{2}{*}{$\begin{array}{l}\text { Manufacturing, } \\
\text { assembly, } \\
\text { integration and } \\
\text { testing }\end{array}$} & \multirow{2}{*}{$\begin{array}{c}\text { QR } \\
\text { SIR } \\
\text { AR } \\
\text { ORR }\end{array}$} & \multirow[t]{2}{*}{$\mathrm{D}$} & \multirow{2}{*}{$\begin{array}{l}\text { Manufacturing, } \\
\text { assembly, } \\
\text { integration and } \\
\text { tests }\end{array}$} & \multirow[t]{2}{*}{$\begin{array}{c}\text { PM\#2 } \\
\text { MAR } \\
\text { FAR }\end{array}$} & \multirow[t]{2}{*}{$\mathrm{D}$} & $\begin{array}{c}\text { Payload } \\
\text { fabrication and } \\
\text { pre-integration } \\
\text { testing }\end{array}$ & PIR \\
\hline & & & & & & & $\begin{array}{l}\text { Integration and } \\
\text { testing }\end{array}$ & MRR \\
\hline EF & $\begin{array}{l}\text { Launching and } \\
\text { closeout }\end{array}$ & $\begin{array}{l}\text { FRR } \\
\text { PFAR } \\
\text { MCR }\end{array}$ & $E / F$ & $\begin{array}{l}\text { Launching and } \\
\text { closeout }\end{array}$ & SLC & $E / F$ & $\begin{array}{l}\text { Launching and } \\
\text { closeout }\end{array}$ & $\begin{array}{l}\text { FRR } \\
\text { MCR }\end{array}$ \\
\hline
\end{tabular}

Comparing the results given in Table 4, the BMP and ELIPS programs are first considered. Taking the latter as a reference, it is observed that the life-cycles although displaying some similarity, present the following main differences and agreements: (a) phases B and C have not been amalgamated, as they have been in the BMP program and, contrariwise, (b) phases 0 and A have been merged, thus also in contraposition to the BMP program. In terms of the review meetings, it is seen that both the BMP and ELIPS life-cycles present departures from the regular review meetings commended by the ECSS standard reference. While in the BMP life-cycle, the PDR and CDR meetings have been substituted by a single design review meeting (DR) in the ELIPS lifecycle, the whole set of review meetings associated to phase D have been simplified to three meetings: the flight acceptance review (FAR) meeting, the module acceptance review (MAR) meeting and the progress meeting 2 (PM\#2), the latter, seemingly, not having the full status of a review meeting. Finally, regarding phases E and F, it should be noted that they have been amalgamated into one phase in both programs.

Now comparing the BMP and NSRP programs, it may be seen that the life-cycles are very similar, the only main difference being that phases 0 and A have been merged in the NSRP program, in contraposition to what is observed in the BMP program. The remaining phases are equivalent, although there are differences in relation to the review meetings corresponding to phase D. Despite the different number of reviews in this phase, considering the descriptions given in Table 4 for phase D BMP review meetings and those given by SSPOD (NASA Goddard Space Flight Center, 2015) for phase D NSRP review meetings, it may be seen that there is an equivalence between the meetings SIR (BPM) and PIR (NSRP), as well as between meetings ORR (BPM) and MRR (NSPR). Thus, even in this respect, there is a significant similarity between the concerned programs.

Concluding this section, it may be stated that the proposed life-cycle for BMP sounding rocket missions presents affinity with both the ELIPS and NSRP life-cycles, with a difference of emphasis on some phases. In the NSFR life-cycle, phases 0 and A, phases $\mathrm{B}$ and $\mathrm{C}$ and phases $\mathrm{E}$ and $\mathrm{F}$ are amalgamated, respectively, into a single phase, which brings about the interpretation that these life-cycle emphasize phase $\mathrm{D}$, since this phase is kept in its entirety. The ELIPS life-cycle, otherwise, emphasizes phases B, $\mathrm{C}$ and $\mathrm{D}$, while the BMP life-cycle emphasizes, in its turn, phases $0, \mathrm{~A}$ and $\mathrm{D}$. These differences in the life-cycles of the three programs reflect, possibly, perceived different needs in each program, that influence the tailoring process of the typical space project life-cycle to each program life-cycle. 


\section{CONCLUSION}

This work aims to propose the tailoring of the project life-cycle commended by the ECSS standard for space missions to sounding rocket missions carried out in Brazil. In this endeavor, the characterization of a sounding rocket mission as a project was first discussed, then the ECSS standard life-cycle for space missions was briefly described and, finally, a tailoring of the latter to sounding rocket missions from Brazilian programs was discussed and proposed.

The project management ECSS standard gives a generic project life-cycle for a typical space project, which, according to ECSS's recommendations, should be tailored to the specific needs of each project or program. Since the execution of a sounding rocket mission as a whole is much simpler than that of a usual space mission, the proposal of tailoring the ECSS generic life-cycle to the needs of sounding rocket missions is quite a natural one.

The tailoring, as mentioned earlier, has been accomplished by taking into account one of the authors experience with Brazilian sounding rocket missions, with the results reflecting what has been perceived as the primary needs of Brazilian sounding rocket missions.

The comparisons carried out previously show that the proposed life-cycle places greater emphasis than the ELIPS (ESA) and NSRP (NASA) programs on the initial activities, concerning the definition, selection of an architecture and planning of the campaign. Table 4 show that while phases 0 and A have been kept in its entirety in the BMP, they have been amalgamated in both the ELIPS and NSRP programs. In the same token, it may also be observed that the ELIPS program places greater emphasis on the design phase of a campaign than both the BMP and NSRP programs. The manufacturing, integration and test phase, otherwise, has been kept as a single phase in all three programs, with simplifications in the review meetings in the case of the ELIPS program. Regarding phases E and F, all three programs display a merging of these phases, arguably due to a short operational phase and relatively standard activities, as regards sounding rocket launching operations.

The authors believe that the shortened life-cycle proposal given in this article represents a fair compromise between the loosening of standard project management practices and mission reliability for the case of Brazilian sounding rocket missions. Aspects of the framework given here are being proposed as inputs for updating current documents or the proposal of new ones that define sounding rocket missions.

\section{AUTHORS' CONTRIBUTION}

Conceptualization: Motta FM and Perondi LF; Methodology: Motta FM and Perondi LF; Investigation: Motta FM and Perondi LF; Writing - Original Draft: Motta FM and Perondi LF; Writing - Review and Editing: Motta FM and Perondi LF; Resources: Motta FM and Perondi LF; Supervision: Motta FM and Perondi LF.

\section{DATA AVAILABILITY STATEMENT}

All dataset were generated or analyzed in the current study.

\section{FUNDING}

Not applicable.

\section{ACKNOWLEDGEMENTS}

Not applicable. 


\section{REFERENCES}

[AEB] Agência Espacial Brasileira (2012) Programa Nacional de Atividades Espaciais: PNAE 2012-2021. Brasilia: Ministério da Ciência, Tecnologia e Inovação.

[COPUOS] Committee on the Peaceful Uses of Outer Space (2015) Status of Zero-Gravity Instrument Project (ZGIP) and Drop Tower Experiment Series (DropTES). Vienna: United Nations Programme on Space Applications.

[ECSS] European Cooperation for Space Standardization (2009) ECSS-M-ST-10C Rev.1 - Space project management: Project planning and implementation. Requirements \& Standards Division. Noordwijk, The Netherlands.

[ECSS] European Cooperation for Space Standardization (2012) ECSS-E-ST-10-03C. Space engineering: Testing. Requirements \& Standards Division. Noordwijk, Netherlands.

[IAE] Instituto de Aeronáutica e Espaço (2019) VS-40. https://www.iae.cta.br/index.php/todos-os-projetos/todos-osprojetos-desenvolvidos/menu-vs-40 - Acessed on 17th june of 2019.

Albuquerque G (2009) Construção e Validação de um Receptor GPS para uso Espacial (Master thesis). Natal: Universidade Federal do Rio Grande do Norte. In portuguese.

[NASA] Space Flight Program and Project Management Handbook. Washington: NASA. (2014)

Garcia A, Yamanaka SSC, Barbosa AN, Bizarria FCP, jung W, Scheuerpflug F (2011) VSB-30 sounding rocket: history of flight performance. J Aerosp Technol Manag 3(3):325-330. https://doi.org/10.5028/jatm.2011.03032211

Kirchhartz R, Horschgen-Eggers M, Jung W (2018) Sounding Rockets are unique Experimental Platforms. 69th International Astronautical Congress. Bremen, Germany.

Kuhl R., Roth M, Binnenbruck H, Dreier W, Forke R, Preu P (2005) The role of sounding rocket microgravity experiments within the German Physical Sciences Programme. Paper presented 17th ESA Symposium on European Rocket and Balloon Programmes and Related Research. Sandefjord, Norway.

Muralikrishna P (2008) Rocket observations of propagating waves in the night time equatorial F-region over Brazil. Adv. Space Res 42(7):1194-1201. https://doi.org/10.1016/j.asr.2007.07.039

[NASA] Goddard Space Flight Center (2015) NASA Sounding Rockets User Handbook. Sounding Rockets Program Office. Sub-orbital and Special Orbital Projects Directorate. Wallops Island: NASA.

Pessoa Filho JB (2014) Personal communication. São José dos Campos.

Pyle R (2019) Space 2.0: How Private Spaceflight, a Resurgent NASA, and International Partners are Creating a New Space Age. Dallas: BenBella Books.

Sabbatini M (2014) ESA User Guide to Low Gravity Platforms - HSO-K/MS/01/14. Brussels: ESA.

Seibert G (2006) The History of Sounding Rockets and Their Contribution to European Space Research. Noordwijk: ESA Publications Division.

Wilson A (2012) ELIPS : Research in Space for the Future. ESA: Paris. 